\title{
A TRADUÇÃo PoÉTICA E OS ESTUdOS CLÁSSICOS NO BRASIL DE HOJE: ALGUMAS CONSIDERAÇÕES
}

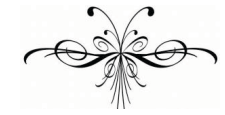 \\ PAulo SÉRGio de VASCONCELlos ${ }^{1}$
}

\begin{abstract}
Resumo: Este artigo discute concepções e atitudes da área de Estudos Clássicos em nosso país no que diz respeito: à noção de tradução "criativa" ou "poética" dos textos; à questão da "literalidade" e "fidelidade" em tradução; à valorização da tarefa tradutória; e à possibilidade e implicações do juízo estético sobre traduções de épocas diversas.
\end{abstract}

Palavras-chave: tradução de poesia clássica; tradução poética; tradução criativa; estudos clássicos no Brasil.

\begin{abstract}
We discuss in this article concepts and attitudes in the area of Classical Studies in Brazil concerning: the notion of "creative" or "poetical" translation; the question of "literality" and "faithfulness" in translation; the appreciation of the translator's task; and the possibility and implications of aesthetic judgments about translations from different ages.
\end{abstract}

Key-words: translation of classical poetry; poetical translation; classical studies in Brazil.

$\mathrm{N}$

ão sou especialista em teoria da tradução, um tema sabidamente complexo, com implicações fillosóficas, lingüísticas, antropológicas, mas, como classicista, em minhas atividades de professor e pesquisador de língua e literatura latina, vejo-me na contingência de traduzir textos em latim que são, na maioria das vezes, literários e, frequentemente, poéticos. Além disso, com certa freqüência participo de bancas de mestrado ou doutorado, avaliando trabalhos que contêm, em maior ou menor extensão, traduções.

Assim, como ocorre com todo classicista, além da prática da tradução, certa reflexão sobre esse tema faz parte de meu cotidiano; sendo o latim uma língua viva apenas através de textos, lidar com traduções e, sobretudo, traduções de textos literários, muitas vezes poéticos, é uma condição inalienável de minhas atividades. Além disso, tenho trabalhado em equipe com as traduções de Odorico Mendes (1799-1864), procurando descrever, a partir das notas do tra-

\footnotetext{
${ }^{1}$ Agradeço à Professora Isabella Tardin Cardoso pela leitura (como sempre atenta e sagaz) do meu texto, suas observações e sugestões.
} 
dutor e dos textos mesmos de suas traduções, uma espécie de laboratório de tradução criativa desse pioneiro da tradução poética no Brasil, segundo a opinião abalizada do poeta e tradutor Haroldo de Campos ${ }^{2}$.

Neste texto, porém, tratarei de aspectos da tradução apenas na medida em que podem fomentar a discussão sobre certas atitudes e práticas que ainda se observam em nosso país, no campo dos Estudos Clássicos (mas não apenas nele!), e que julgo, justamente, discutíveis. Aspectos da questão tantas vezes debatidos só me interessarão aqui se auxiliam a uma (auto)crítica envolvendo a área de Estudos Clássicos e seus pressupostos explícitos ou implícitos. Interessa-me colocar em discussão, sobretudo: a tópica da fidelidade ao sentido, o fetiche da tradução literal, a rejeição (cada vez menor, por sinal) à tradução criativa dos textos poéticos.

Tenho observado, ao longo dos últimos anos, que ainda resiste um antigo topos que abre tantas apresentações de trabalhos acadêmicos e, mesmo, de livros da área: a profissão de fé de que, na tradução de textos literários, sobretudo poéticos, preferiu-se ser fiel ao original. Eu mesmo, há vinte anos atrás, ${ }^{3}$ utilizei-me dessa tópica de forma ingênua, pagando tributo a esse locus communis. Quantos prefácios não trazem tal declaração de princípio, uma captatio beneuolentiae meio acanhada, prevendo um crítico que se incomodasse com uma tradução não poética - ou mesmo literária - de um texto poético?

Em mais de uma ocasião, em palestras e artigos, mencionei como essa pretensão de fidelidade é ingênua, quando, por exemplo, ao se traduzir poesia, não há preocupação em (re)criar na língua de chegada efeitos de som e ritmo análogos aos que se percebem na língua de partida e se apregoa, então, fidelidade ao sentido, esquecendo-se que som e ritmo, como parte material do significante, indissociável do significado, são parte do sentido. Por vezes, sob tal divisa, tratando-se de "reproduzir" o significado, não há nem mesmo a preocupação em manter o que de mais singular, em termos semânticos, teria determinada expressão do original, fazendo-se tábua rasa do que de estranhamento poderia ela ter provocado em leitores contemporâneos à produção e divulgação primeira da obra.

Tenho a impressão de que, por vício da tarefa ancestral de explicação dos textos, tendemos por vezes a traduzir escolhendo palavras e expressões que acabam criando como que uma versão simplificadora de tudo o que o original possa ter de difícil, enigmático, impreciso, vago.

Nesse tipo de tradução, parece que a preocupação central é aparar qualquer aresta do texto, propondo ao leitor algo fluente e fácil, de compreensão mais imediata. Em princípio, nada tenho contra essa postura, que se poderia chamar "didática", desde que esteja consciente de seus pressupostos e limites e desde que, em sua defesa, não se use como justificativa uma fidelidade ao sentido que, independentemente dos aspectos propriamente literários, não possui.

\footnotetext{
2 "No Brasil, não nos parece que se possa falar no problema da tradução criativa sem invocar os manes daquele que, entre nós, foi o primeiro a propor e a praticar com empenho aquilo que se poderia chamar uma verdadeira teoria da tradução. Referimo-nos ao pré-romântico maranhense Manuel Odorico Mendes" (Metalinguagem \& outras metas. $4^{\mathrm{a}}$. edição revista e ampliada. São Paulo: Perspectiva, 1992, p. 38).

${ }^{3} \mathrm{Na}$ introdução a minha tradução de Catulo em CATULO. O cancioneiro de Lésbia. São Paulo: Hucitec, 1991.
} 
Não se é fiel ao sentido da letra do texto ao apresentar-se ao leitor uma interpretação banal da expressão densa e marcada do original.

Ilustro brevemente com uma expressão de um verso das Geórgicas de Virgílio:

\section{Vmida solstitia atque hiemes orate serenas (I, 100)}

Odorico Mendes traduz: "Rogai solstício aguado e inverno claro"... (101). Nas notas à tradução das Geórgicas, o tradutor avisa ao leitor que "solstício" significa, em tal passagem, verão. ${ }^{4}$ A explicação facilita a leitura, que, sem ela, exigiria um raciocínio, uma reflexão para se compreender o sentido do termo no contexto. O original traz solstitia, "solstícios", que pode, como seu equivalente em português, designar tanto o solstício de verão quanto o de inverno, mas, em certos contextos, designa o de verão. Por sinédoque, torna-se sinônimo de "verão" (ver $O L D$, que cita, da época de Augusto, para abonar o sentido de "the period of the summer solstice" (2b), este passo e um verso de Horácio, além de um verso das Bucólicas -VII, 47 do mesmo Virgílio). Que a expressão deveria provocar estranhamento no próprio latim é atestado pela extensa nota de Sérvio à passagem. Odorico molda o português à semelhança do latim de Virgílio. Nos dicionários de língua portuguesa não há registro da palavra "solstício" como sinédoque para "verão"; mas o leitor da tradução, mesmo sem a advertência da nota de Odorico, entenderia, pelo contexto, que é disso que se trata, já que "solstício" vem contraposto a "inverno". Eis uma pequena amostra de como aquele tradutor não traduz explicando e facilitando, banalizando; pelo contrário, cria em português uma sinédoque decalcada no latim. Temos, aqui também, um pequeno exemplo de influência da língua de partida sobre a língua de chegada, modelada para reproduzir o jogo semântico do original. A título de confronto com outras traduções poéticas, vejam-se algumas soluções: Delille traz "étés humides"; Cândido Lusitano, "Verões úmidos"; Pina Leitão, "úmidos estios"; Agostinho da Silva, "verões chuvosos". 5

Traduções supostamente fiéis ao sentido muitas vezes aparam tudo o que o original possa ter de especioso; o novo texto oferece uma interpretação esclarecedora, em vez de criar um equivalente tão impreciso, obscuro, difícil quanto o original.

É claro que esta última postura implica um risco: o novo texto se torna mais difícil e essa dificuldade contribui para que sua tradução seja tachada de obscura ou, no limite, ilegível, como, de fato, ocorreu com Odorico Mendes. Assim como, na explanação de frases no interior de uma mesma língua, usamos artifícios retóricos e discursivos que traduzem esclarecendo, substituindo o

\footnotetext{
4“O solstício aqui toma-se pelo verão" (MENDES, Manuel Odorico, Virgilio Brazileiro. Paris: Na Typographia de W. Remquet, 1858, p. 101).

${ }^{5}$ DELILLE, J. Les Géorgiques de Virgile traduites en vers français. Paris: L. G. Michaud, 1819; LUSITANO, Leonel da Costa. As éclogas, e Georgicas de Vergilio. Lisboa: Na officina de Miguel Manescal da Costa, 1766; PINA, Antonio José Ozorio de. Tradução livre ou imitação das Georgicas de Virgilio. Lisboa: Tipografia Nunesiana, 1794; VIRGÍlLIO. Obras de Virgílio. Tradução do latim do Prof. Agostinho da Silva. $2^{a}$.ed., Lisboa: Temas e Debates, 1999. Cf. SaintDennis, na série Belles Lettres: "solstices humides" (VIRGILE, Géorgiques. Paris: Les Belles Lettres, 1982, p. 5).
} 
enunciado original por um outro que o decifre, ${ }^{6}$ certa postura tradutória apresenta, como produto final, um texto que oferece ao leitor um texto que é o resultado da operação interpretativa que, segundo a leitura do tradutor, a interpretação do texto exigia e de que se poupa o leitor. Traduções que recriam polissemias, ambigüidades, imprecisões semânticas certamente deixam ao leitor um espaço maior para a interpretação.

Portanto, não é apenas o lado material dos signos que frequentemente é sacrificado em traduções não poéticas, por vezes mesmo em traduções que se pretendem poéticas: ao facilitar o texto na versão, também o aspecto mais desafiador do significado do original desaparece da tradução. Esse tipo de tradução "explicativa", porém, não é exclusivo da área de estudos clássicos, tanto assim que falamos, de modo geral, em traduções que são verdadeiras paráfrases do original.

Volto ao antigo dilema: tradução mais presa ao sentido literal ou recriação do original? Mas será que existe uma tradução qualquer que não seja recriação do original? Não seria mais adequado falar em modalidades de recriação? Depois de muito mencionar, em ocasiões variadas, o conceito de tradução poética como recriação (ou "transcriação"), nas pegadas de Haroldo de Campos, que o difundiu em nosso país, ${ }^{7}$ tendo hoje a crer que toda tradução, de qualquer tipo de texto, qualquer tradução, é uma recriação; por mais que se busque criar uma analogia cerrada dos aspectos textuais que se pretende ver no original, trata-se de um dizer em outro sistema lingüístico, sujeito às implicações desse sistema que não estavam previstas no original.

E não se dirá que é um dizer o mesmo em outro sistema lingüístico: não se dirá o mesmo, jamais, e se proporá, em vez disso, uma reconstrução, uma interpretação do que se leu no original e que se pretende verter em outra língua: enfim, não uma reprodução, propriamente, mas uma (re)criação condicionada pelo original. No caso dos clássicos, ainda temos, previamente à tradução, um estabelecimento de texto que se baseou em leituras singulares, interpretação e seleção entre opções de manuscritos diversos; o texto a traduzir já foi submetido a uma primeira leitura, sempre passível de discussão, o que mostra quão instável é o original que certa postura tradutória parece tratar como um objeto fixo no tempo, um código a ser decifrado e que o será, certamente, se o tradutor tiver a competência necessária.

Por vezes, parecemos imitar as pretensões de fidelidade de um Pierre Ménard ${ }^{8}$ na tarefa de reescrever, não o Quixote, mas os textos latinos e gregos

\footnotetext{
${ }^{6}$ Sobre o processo de "reenunciação" na mesma língua, veja-se STEINER, George. Depois de Babel. Questões de linguagem e tradução. Curitiba: UFPR, 2005, p. 282; JAKOBSON, Roman, "Aspectos lingüísticos da tradução" In JAKOBSON, Roman. Linguistica ecomunicação. São Paulo: Cultrix, 1975, p. 64-65.

7،Admitida a tese da impossibilidade em princípio da tradução de textos criativos, parece-nos que esta engendra o corolário de uma outra possibilidade, também em princípio, da recriação desses textos. Teremos...em outra língua, uma outra informação estética, autônoma, mas ambas estarão ligadas entre si por uma relação de isomorfia: serão diferentes enquanto linguagem, mas, como os corpos isomorfos, cristalizar-se-ão dentro de um mesmo sistema" (CAMPOS, Haroldo de. Metalinguagem \& outras metas. São Paulo: Perspectiva, 1992, p. 34).

${ }^{8}$ Steiner usa a figura paradigmática do personagem borgiano para refletir sobre a tarefa tradutória e concluir: "Em outras palavras, qualquer ato genuíno de tradução é, pelo menos sob um ponto de vista, um cristalino disparate, um esforço para reverter para cima a escada rolante do tempo e reconstituir voluntariamente o que era um movimento contingente do espírito" (STEINER, Op. cit., p. 98.). O problema surge quando, sem percebermos, acreditamos que é
} 
com que lidamos. Modernamente nos acostumamos a colocar sob suspeita a idéia de que o texto literário (ou ainda qualquer texto) tem um sentido único a ser decifrado pelo pesquisador, que, munido dos instrumentos filológicos adequados, encontraria a chave de seu sentido. Pensar na tradução a partir dessa perspectiva nos leva a maior humildade: o tradutor lê o original, interpreta-o e, a partir dessa interpretação, recria-o em sua língua: em contexto de tanta incerteza, em terreno tão móvel, é demasiado ingênuo tratar a tradução como reprodução fiel do sentido e, sob essa bandeira, julgar criticamente as traduções. Considerar toda tradução como recriação tem a vantagem de abandonar qualquer pretensão ingênua de reprodução fiel do original.

Textos, no processo tradutório, não são passíveis de reprodução, apenas de recriação. No trabalho de recriação, porém, há modalidades diversas e diferentes graus de dificuldade. Textos mais informativos, em que o trabalho com a linguagem é menos importante, são recriados em outra língua de modo reconhecidamente mais fácil, sobretudo se a tradução se dá entre línguas de culturas próximas. As dificuldades, nesse caso, surgem quando há distância cultural ou perda da referência; assim, traduzir certas receitas de Apício (século I d. C.) oferece a dificuldade de se compreender a que ingredientes precisos se refere determinada receita. Identificados os ingredientes, o conteúdo informativo do texto se transferirá para outra língua com relativa facilidade.

A fidelidade ao sentido por vezes parece supor ingenuamente que haja correspondências exatas entre uma língua e outra, como se fosse possível abolir as peculiaridades de cada língua, sua diversidade intrínseca. Supondo que determinado substantivo latino, por exemplo, pater, tenha um equivalente em "pai" do português, é prudente lembrar que em cada língua o substantivo respectivo se imanta de conotações diversas, não reproduzíveis com a simples troca de um pelo outro. Esqueçamos por um momento que pater pode designar não apenas o pai biológico, mas o chefe de família, que pode ser o que chamaríamos um avô - ainda assim, pater pode evocar, para um romano, uma aura de poder que não se vê tão claramente em seu equivalente português. É claro que há uma fronteira de sentido comum, ou não seria possível entendermos o texto e o mundo antigo, mas essa consideração nos deve advertir para uma ingênua crença na tradução literal como a resolução de uma equação matemática cujo resultado seria a tradução perfeita ou, pior ainda, a única admissível. Como diz Bruno Gentili: "O ideal da reprodução fiel ou da reprodução integral do significado de um texto representa, substancialmente, uma verdadeira ilusão"".

Nenhuma tradução é literal, já que não existe correspondência exata entre uma língua e outra. No campo do significado, há apenas fronteiras comuns que são apenas metade ou menos da história, como se ilustra com o singelo exemplo "pater"/"pai". Essa diversidade pode se aplicar a outros aspectos como a ordem das palavras, etc. Exercícios de tradução em sala de aula parecem corroborar para a crença numa equivalência precisa. Mas, quando se traduz literalmente, em aulas de gramática, criam-se, da forma mais artificial, frases

possível re-produzir o Quixote, apagando as marcas da história; reproduzido palavra por palavra, o Quixote significaria, inapelavelmente, outra coisa em outra época.

"'l'ideale della resa fedele, o della resa integrale del significato di un testo, rappresenta in sostanza una vera illusione" (GENTILI, Bruno. Tradurre Poesia. In: Salvatore Nicosia (a cura di). La traduzione dei testi classici. Teoria prassi storia. Atti del convegno di Palermo. Napoli: M. D’Auria, 1998, p. 31). 
monstruosas, no limite da agramaticalidade, para se ser didático; traduções assim no fundo mostram como as línguas, quando tentamos fazê-las corresponder ao máximo, mostram-nos sua diversidade.

Em suma, tradução literal é um conceito demasiado complexo ${ }^{10}$; se tomado no sentido de verter palavra por palavra, literalmente, não existe tradução integralmente assim. Por outro lado, vimos que traduções supostamente fiéis ao sentido literal parecem fugir do literal quando ele produziria estranhamento ao leitor contemporâneo: assim, esse tipo de tradução evitaria, por exemplo, traduzir aquele solstitia virgiliano por "solstícios". A postura inversa cria decalques semânticos e sintáticos do original, tornando a tradução menos óbvia, mais difícil e permitindo que o influxo de uma língua por outra se dê em vários níveis (recriação do léxico, novas metáforas, etc. $)^{11}$.

Certa tradição filológica parece ver como um pecado de lesa-filologia a não "reprodução" de dados do texto que o situem numa outra cultura, num outro tempo; nesse tipo de consideração, utilizar, por exemplo, um termo do mundo moderno na recriação de um texto antigo é um sacrilégio supremo.

Nada tenho contra a postura filológica típica, aliás, pessoalmente, prefiro traduções que mantenham dados referenciais do texto original (da cultura material, as marcas de certa ideologia, etc.) que causem estranhamento por serem diferentes da nossa realidade, não se apagando o que constitui marcas da alteridade de uma outra cultura nele impressas. Mas quem adota essa postura não pode pretender que, no seu trato com o texto, esteja mais próximo do Texto em sua essência, mais próximo do Sentido, único e estável, um fóssil que o arqueólogo dos sentidos traria à luz em sua plenitude, depois de tirar o pó da história que sobre ele se teria acumulado... Algumas traduções deixam mais à vista o fato de que não há transparência na tarefa da tradução, como não há no processo de interpretação; outras procuram escamotear essa condição como se pudessem recriar o original à la Pierre Ménard.

O que me parece inaceitável é que a academia rejeite traduções que recriam poeticamente o original em nome de uma fidelidade ao sentido que trai concepções positivistas.

O trabalho filológico fornece ao tradutor elementos importantes para a compreensão do texto a traduzir; as traduções poéticas, que por vezes traem o sentido literal para não trair o poético, são um meio eficaz de fazer os textos literários da Antiguidade chegarem ao leitor moderno e terem impacto sobre a vida cultural. Traduções acadêmicas, eruditas, cheias de notas de rodapé, mesmo carentes do trabalho estético com a língua que é próprio do poético, podem também ter seu público fora da academia e seu papel de divulgação dos clássicos. Como prova disso, vêem-se várias editoras recorrerem à academia solicitando traduções dos clássicos para publicá-las, mesmo que sejam traduções não

\footnotetext{
${ }^{10}$ Borges explora em um ensaio o saboroso paradoxo de traduções literais produzindo enunciados interessantes em seu estranhamento, como, por exemplo, na expressão "Cântico dos cânticos", versão literal de uma forma de superlativo comum na língua hebraica. Veja-se BORGES, Jorge Luis. Esse ofício do verso. São Paulo: Companhia das Letras, 2000, p. 64-81.

${ }^{11}$ Um tipo de tradução examinado por Schleimacher (1768-1834), o tradutor de Platão, em seu ensaio "Ueber die verschiedenen Methoden des Uebersezens", que se pode ler em tradução para o português: "Sobre os diferentes métodos de tradução" in: HEIDERMANN, Werner (org.). Clássicos da teoria da tradução. Volume I. $2^{\mathrm{a}}$. edição revisada e ampliada, Florianópolis: Universidade Federal de Santa Catarina/Núcleo de Pesquisas em Literatura e Tradução, 2010, p. 37101.
} 
poéticas de textos poéticos. Não se trata de campos de ação excludentes, mas de faces diversas do trabalho com os textos antigos, que os mantém vivos, influentes, significativos, cada um à sua maneira, com suas concepções e métodos próprios.

O texto poético permite ao tradutor uma gama ampla de apropriações do original, desde aquela que passa por cima desse aspecto, ignorando-o, simplesmente, até aquele tipo de tradução que pretende recriar em outra língua efeitos de som, ritmo, ordem das palavras comparáveis ao que há, ou melhor, julgase haver no original.

Explico o “julga-se haver”. Por mais que seja verossímil que a configuração sonora e rítmica do texto tenha relevância, esteja inscrita na "intenção da obra", esse aspecto do texto nos chega através de uma leitura do original, não se podendo pretender, pois, que essa leitura pessoal, por mais convincente que seja, apoiada nos melhores métodos da filologia, se apresente, em sua fidelidade ao poético, como a tradução que de fato reproduz mais fielmente o original: ela não reproduz o original, recria o que seu tradutor leu e interpretou no/do original. Há aqui o perigo de passar de Cila a Caribdis: quem recria os efeitos poéticos do original também não pode ter a pretensão de ter descoberto a chave única de interpretação desse texto e que sua leitura dos efeitos poéticos do original, pautada em critérios específicos, é a única possível. A tradução é, sempre, uma certa leitura do original, consubstanciada num texto novo em uma língua diversa, com todas as implicações dessa prática.

Vimos, brevemente, que a tópica da fidelidade ao sentido parece trair por vezes a crença de que haveria uma tradução ideal que apresentasse como que a chave interpretativa de um código a ser decifrado. Não é essa uma atitude exclusiva da área, como ilustraremos.

Recentemente, Cláudio Abramo publicou um livro que analisa criticamente traduções várias do poema $O$ Corvo de Edgar Allan Poe. ${ }^{12}$ A tese de Abramo é que, ao se dar maior importância à recriação de ritmo e som na língua de chegada, o tradutor trai o original, porque é infiel ao sentido. É curioso como o autor insiste na tradução do sentido, por oposição à forma, falando inclusive em "precisão semântica" e passando por cima da idéia, hoje consensual, de que som e sentido são entidades indissociáveis, como resume Ricoeur:

A imensa maioria dos tradutores resiste, e sem dúvida, sob o modo do salve-se quem puder, sem reconhecer que traduzir o sentido apenas é renegar uma aquisição da semiótica contemporânea, a unidade do sentido e do som, do significado e do significante.... ${ }^{13}$

Abramo tece uma crítica à teoria da recriação dos textos poéticos, ${ }^{14}$ que tem como alvo seu principal divulgador no Brasil, o já mencionado Haroldo de Campos. O curioso é que seu livro apresenta várias traduções poéticas de $O$ Corvo, como as célebres versões de Machado de Assis e de Fernando Pessoa, precedidas de uma tradução em prosa que seria fiel ao sentido literal. Eis a maior contraprova do que diz o livro, já que essa tradução prosaica é, por certo, a

\footnotetext{
${ }^{12}$ ABRAMO, Claudio Weber. O Corvo. Gênese, referências e traduções do poema de Edgan Allan Poe. São Paulo: Hedra, 2011.

${ }^{13}$ RICOEUR, Paul. Sobre a tradução. Belo Horizonte: UFMG, 2011, p. 69-70.

${ }^{14}$ P. 24-28.
} 
pior das que o livro estampa; pior, porque menos interessante como texto. ${ }^{15}$ Abramo adverte que sua tradução não tem "pretensão literária"; assim mesmo, sua tradução do que seria o sentido do poema mostra como essa suposta fidelidade ao sentido não é suficiente para produzir um texto literário. Ou seja, uma tradução centrada na reprodução supostamente fiel dos sentidos literais do texto produz a maior das infidelidades do ponto de vista da criação literária: um texto que nem de longe lembra um trabalho com a linguagem que se possa chamar de estético. Como diz Valéry:

É que os mais belos versos do mundo ficam insignificantes ou sem sentido, uma vez rompido seu movimento harmônico e alterada sua substância sonora, que se desenvolve em seu tempo próprio de propagação mensurada, e são substituídos por uma expressão sem necessidade musical intrínseca e sem ressonância. $^{16}$

Numa formulação como "De todas as traduções feitas para o português, a de Rubens Francisco Lucchetti, publicada em 1976, é a única que se apresenta na forma de prosa. Isso permitiu resguardar essencialmente o sentido do original"17, fica patente, em Abramo, a redução do sentido à suposta reprodução "fiel" do significado superficial, como se sons e ritmo não fizessem parte do sentido de uma obra poética.

No entanto, na tradução de textos poéticos, Abramo distingue a tradução literal, que ele rejeita, da que seria fiel ao sentido, que ele apregoa como ideal. Ao rejeitar, porém, as traduções poéticas em nome da fidelidade ao sentido, Abramo reduz "sentido", excluindo deste os efeitos de som e ritmo, como se só veiculassem um sentido as palavras tomadas isoladamente, despidas de sua substância material. De novo, invoquemos Valéry: "em se tratando de poesia, a fidelidade restrita ao sentido é uma forma de traição" 18 .

Essa postura de Abramo é aqui mencionada porque acredito que em nossa área ainda subsistam posturas semelhantes diante do texto literário. Não quero dizer que um certo tipo de tradução dos sentidos não tenha seu papel. Mas acho que, em nome do rigor filológico, desconsiderar traduções que têm a finalidade de recriar em outra língua os efeitos mais ligados ao aspecto material da língua é uma atitude equivocada e contraproducente. Ressalto, por outro lado, que essa rejeição é hoje marginal.

Há certamente uma tradução de texto literário que, atenta ou não aos aspectos poéticos do original, tem preocupações que poderíamos dizer filológicas. Antes de mais nada, em nossa comunidade acadêmica, uma tradução que revele ter o tradutor compreendido mal o texto que se traduziu (por entendimento incorreto da língua original) não desfrutará de prestígio. Além disso, nesse tipo de recriação, respeitam-se todas as referências a aspectos da cultura contem-

\footnotetext{
${ }^{15}$ P. 65-69. Sobre a (im)pertinência do juízo estético aqui expresso, veja-se o que dizemos mais adiante.

16 “C'est que les plus beaux vers du monde sont insignifiants ou insensés, une fois rompu leur mouvement harmonique et altérée leur substance sonore, qui se développe dans leur temps propre de propagation mesurée, et qu'il sont substitués par une expression sans necessité musicale intrinsèque et sans résonance." VALÉRY, Paul. Traduction en vers des Bucoliques de Virgile précédée de variations sur les Bucoliques. Paris: Gallimard, 1956, p. 23.

${ }^{17}$ P. 137.

18 “s'agissant de poésie, la fidélité restreinte au sens est une manière de trahison" (Ibidem).
} 
porânea à produção do texto, em vez de dar-lhes equivalentes modernos; o leitor não especialista terá de ler notas ou recorrer a obras de referência para compreender esses dados do novo texto. No limite, certas passagens dessas traduções só serão compreensíveis quando esclarecidas por notas; traduções acadêmicas, sabemo-lo bem, em geral estão repletas de notas como se o tradutor não deixasse jamais de lado seu papel de explicador dos textos. Insistamos: esse tipo de tradução tem seu papel, sua importância, seus leitores.

A tradução criativa, entendida como "transcriação", foi alvo de certo preconceito da academia no Brasil até há pouco tempo. Não quero defender esse tipo de postura do tradutor por si mesmo ou exaltá-lo como o modo ideal de traduzir, e sim criticar uma rejeição que se baseie em concepções do texto muito discutíveis, sobretudo numa concepção positivista da obra que renega sua alteridade, seu papel de objeto contextualizado numa cultura e numa língua diversas, ancorado em seu ambiente histórico e afetado pela história inapelavelmente. Como toda teoria, a da "transcriação" é sujeita a crítica, mas que ela não seja feita em nome de uma traição a supostos princípios filológicos universais e trans-históricos que produziriam uma tradução fiel ao sentido estável, único, muito bem definido, do original. ${ }^{19}$

Uma outra questão é a do prestígio social do tradutor. Maior consciência da importância de sua tarefa parece ser um fenômeno mundial. Em se tratando de obras literárias, sobretudo, não vemos mais faltar, em nosso país, numa publicação, a indicação do nome do tradutor ou não ser dado a este nenhum destaque, como no passado por vezes ocorria.

Gostaria, porém, de expor um caso curioso, que demonstra como ainda temos certa resistência em assumir a tarefa tradutória como ato de (re)criação. Na coleção de clássicos bilíngues da UNICAMP, denominada Lumina, pensouse, de início, em valorizar a tarefa do tradutor e o fato de que a tradução cria um novo texto a partir de outro. O primeiro título da coleção trazia na capa o nome da tradutora (minha colega Isabella Tardin Cardoso $)^{20}$ como autora e depois o nome da obra e do autor do original (Estico de Plauto). Mas a editora depois voltou atrás, rejeitando esse procedimento como equivocado. Note-se que, além da tradução, a obra traz um estudo extenso e mais de 250 notas de rodapé à tradução.

Percebo que esse modo de indicação de autoria de fato é polêmico e que até mesmo especialistas em teoria da tradução não o aceitam. Entretanto, chamo a atenção para a atitude de Odorico Mendes, que, nas pegadas da Eneida portuguesa de João Franco Barreto, chamou sua tradução da Eneida de "Eneida Brasileira", causando, aliás, uma dificuldade para os editores, afinal como referenciar a obra? Como indicar o autor de uma "Eneida Brasileira"? Virgílio? Odorico Mendes? Os dois e nem um nem outro individualmente, duas obras cuja relação dialógica se marca fortemente: mais uma surpresa dentre as muitas

\footnotetext{
${ }^{19} \mathrm{Na}$ área de estudos clássicos no Brasil posturas teóricas pós-modernas, que desestabilizam a noção de texto como objeto fechado em si mesmo, parecem ter ainda pouca influência. Para uma concepção pós-moderna da tarefa tradutória, veja-se (fora de nossa área) ARROJO, Rosemary. "Postmodernism and the teaching of translation". In: Cay Dollerup; Vibeke Appel (ed.). Teaching translation and interpreting 3. New horizons. Papers from the third Language International Conference. Amsterdam/Philadelphia: John Benjamins Publishing, 1995, p. 97103.

${ }^{20}$ CARDOSO, Isabella Tardin. Estico de Plauto. Campinas: Editora da UNICAMP. 2006.
} 
que nos reserva o projeto de Odorico Mendes, baseado em sólido conhecimento filológico, mas tratando a tradução como uma recriação e um texto poético com relativa autonomia. Uma Eneida que se intitula "brasileira" revela a consciência de que não se reproduz o original, mas que dele o tradutor se apropria e a partir dele cria obra com uma marca própria vistosamente estampada no próprio título.

Trato agora da crítica de traduções. Compreender cada tradução realizada no passado em seu contexto é uma petição de princípios mais do que justificada; trata-se de compreender os parâmetros que remetem a um gosto que pode não ser o do crítico moderno. Mas, ainda assim, não julgo ilícito o nosso juízo estético, desde que consciente de sua relatividade. Se todas as traduções forem apreciadas por seus próprios critérios, mais ou menos explícitos, não poderemos dizer que haja tradução ruim ou que uma supere outra esteticamente: todas têm, afinal, seus pressupostos específicos. O bom senso mostra a fatuidade dessa postura, que, em nome da historicidade e relatividade do juízo, resvala numa espécie de ato politicamente correto de suspensão do juízo.

De novo, não é possível negar a história e apreciar objetos estanques em sua qualidade de produtos culturais de certa época a que poderíamos ter acesso direto, não permeado por nossa subjetividade. Se eu preferir certa tradução de um verso virgiliano realizada por Odorico Mendes à de um outro tradutor, de outra época, não exporei meu juízo estético como a verdade cabal, mas como uma opinião que tentará persuadir pela apresentação de certas análises dos dois textos confrontados entre si e com o original: trata-se de retórica consciente de ser retórica.

Preferir apreciar o texto de acordo com as preceptivas de época e de seu autor e suspender o juízo estético é acolher uma outra retórica, nefasta apenas quando se pretende mais fiel a uma suposta verdade histórica, não se dando conta do peso da história sobre o nosso trato com os textos e da subjetividade inerente a toda narrativa que teçamos sobre eles. Duas retóricas se confrontam, cada uma com seu poder de persuasão, ambas em busca, não da Verdade, mas de um probabile que, entre a comunidade interpretativa dos classicistas e entre a comunidade mais ampla dos leitores de poesia, convencerá a uns e deixará outros céticos. Em que pese a instabilidade que tal postura instaura em nossas crenças quanto à ciência e à verdade, não há nenhum motivo para lamentação, porém: aqui parecem-nos aplicáveis estas palavras de Alessandro Barchiesi em referência às análises intertextuais:

Nossa pesquisa é parte de toda atividade humanística normal: é imprecisa, conjetural, retórica e subjetiva. Mas não há disciplina das humanidades ultimamente que tenha ficado imune a esse tipo de autocrítica. ${ }^{21}$

Por fim, não traço um quadro pessimista da tradução dos clássicos em nosso país, pelo contrário: o número de traduções é muito maior do que o de há algumas décadas atrás; traduções de clássicos realizadas por professorespesquisadores da área têm concorrido ao Prêmio Jabuti e mais de uma vez o ga-

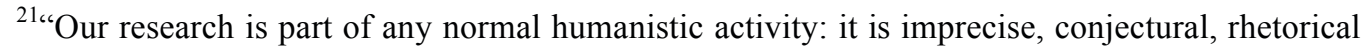
and subjective. But there is no discipline in the humanities lately which has remained immune from this sort of self-criticism." BARCHIESI, Alessandro. Speaking volumes. Narrative and intertext in Ovid and other Latin poets. London: Duckworth, 2001, p. 143.
} 
nharam ${ }^{22}$; traduções de texto literário com pretensões mais altas são mais bem aceitas; várias editoras estão abertas à publicação dos clássicos. Por fim, discussão sobre a tarefa do tradutor tem sido realizada em nossa área, tornando todo o processo de tradução dos clássicos, entre nós, menos automático, mais ponderado, mais reflexivo. Assim como no âmbito da interpretação literária, a rejeição à teoria é cada vez menor.

Em comparação com o quadro que víamos há algumas décadas, demos um salto qualitativo na produção de traduções de textos literários, na reflexão crítica sobre a tradução em geral, no estudo da recepção e crítica das traduções. Este é mais um dos vários dados que atestam o recente reflorescimento dos estudos clássicos no Brasil, cujo vigor tem provocado a admiração dos estudiosos estrangeiros que participam de eventos realizados em nosso país.

Paulo Sérgio de Vasconcellos odoricano@ig.com.br Universidade de Campinas

\footnotetext{
${ }^{22}$ Em 2009, a tradução do Satiricon de Petrônio por Cláudio Aquati; em 2008, Hipólito e Fedra, de Joaquim Brasil Fontes, e o Agamêmnon de Ésquilo, por Trajano Vieira. Acrescente-se o prêmio da APCA concedido a O livro de Catulo, de João Angelo Oliva Neto, em 1996.
} 


\section{Referências bibliográficas}

Abramo, Claudio Weber. O Corvo. Gênese, referências e traduções do poema de Edgan Allan Poe. São Paulo: Hedra, 2011.

Arrojo, Rosemary. Postmodernism and the teaching of translation. In: Cay Dollerup; Vibeke Appel (Ed.). Teaching translation and interpreting 3. New horizons. Papers from the third Language International Conference. Amsterdam/Philadelphia: John Benjamins Publishing, 1995, p. 97-103.

BARCHIESI, Alessandro. Speaking volumes. Narrative and intertext in Ovid and other Latin poets. London: Duckworth, 2001.

Borges, Jorge Luis. Esse ofício do verso. São Paulo: Companhia das Letras, 2000.

CAMpos, Haroldo de. Metalinguagem \& outras metas. $4^{\text {a }}$. edição revista e ampliada. São Paulo: Perspectiva, 1992.

CARdoso, Isabella Tardin. Estico de Plauto. Campinas: Editora da UNICAMP. 2006.

CAtulo. O cancioneiro de Lésbia. São Paulo: Hucitec, 1991.

Delille, J. Les Géorgiques de Virgile traduites en vers français. Paris: L. G. Michaud, 1819.

Gentili, Bruno. Tradurre Poesia. In: Salvatore Nicosia (a cura di). La traduzione dei testi classici. Teoria prassi storia. Atti del convegno di Palermo. Napoli: M. D’Auria, 1998, p. 31-40.

HeidermanN, Werner (Org.). Clássicos da teoria da tradução. Volume I. $2^{\mathrm{a}}$. edição revisada e ampliada, Florianópolis: Universidade Federal de Santa Catarina/Núcleo de Pesquisas em Literatura e Tradução, 2010.

JAKOBSON, Roman. Aspectos lingüísticos da tradução. In: JAKOBSON, Roman. Linguistica e comunicação. São Paulo: Cultrix, 1975, p. 63-72.

Lusitano, Leonel da Costa. As éclogas, e Georgicas de Vergilio. Lisboa: Na officina de Miguel Manescal da Costa, 1766.

Mendes, Manuel Odorico, Virgilio Brazileiro. Paris: Na Typographia de W. Remquet, 1858.

PINA, Antonio José Ozorio de. Tradução livre ou imitação das Georgicas de Virgilio. Lisboa: Tipografia Nunesiana, 1794.

RICOEUR, Paul. Sobre a tradução. Belo Horizonte: UFMG, 2011.

SteIner, George. Depois de Babel. Questões de linguagem e tradução. Curitiba: UFPR, 2005.

VALÉRY, Paul. Traduction en vers des Bucoliques de Virgile précédée de variations sur les Bucoliques. Paris: Gallimard, 1956.

Virgílio. Obras de Virgílio. Tradução do latim do Prof. Agostinho da Silva. $2^{a}$.ed., Lisboa: Temas e Debates, 1999.

VirgiLe, Géorgiques. Texte établi et traduit par E. de Saint-Denis. Paris: Les Belles Lettres, 1982. 